\title{
Study on Kinetics of Hydraulic Prop Crawling Phenomenon
}

\author{
Rong-jie Wang ${ }^{1, a}$, Hong-wei Chen ${ }^{2, b}$ \\ ${ }^{1}$ Department of Mechanical and Electrical Engineering, Longyan University, Longyan, Fujian, \\ 364012, China \\ ${ }^{2}$ Department of Mechanical and Electrical Engineering, Longyan University, Longyan, Fujian, \\ 364012, China
}

a13859506650@139.com, ${ }^{\mathrm{b}} 13626028318 @ 139 . c o m$

Keywords: hydraulic prop; crawling; dynamics; analysis.

\begin{abstract}
Crawling is a common phenomenon during the operation of hydraulic prop. Through analyzing the causes of crawling phenomenon, establishing the dynamic model and mathematical expression of crawling, the result is that when the minimum speed of the pillar stretch motion is higher than the critical speed, reducing the normal force on the guide rail, selecting good sealing and reasonable sealing structure to prevent the air from mixing with the hydraulic oil, the crawling phenomenon could be avoided.
\end{abstract}

\section{Introduction}

In practice, hydraulic prop often has obvious speed fluctuation phenomenon, that is, speed turn from fast to slow or from stopping into jumping. This abnormal motion is called crawling, which reduces the support force and affects the supporting performance. At present, there are plentiful analysis of the harm and the causes of hydraulic prop crawling phenomenon, however, the research on dynamics of the crawling phenomenon is rare. Therefore, the analyzing the kinetics of hydraulic prop crawling phenomenon and calculating factors that related to crawling have vital significance to improve the hydraulic prop supporting effect and production safety.

\section{Individual hydraulic prop structure and supporting principle}

The use of coal mine in Fujian province is the external injection type single body hydraulic prop, its structure as shown in figure 1 . When using liquid injection gun is inserted into the injection hole clenched hand, liquid injection, high pressure liquid will be one-way valve is opened, into a single column of inferior vena cava, rises to the top so as to make the movable column, single column contact with the coal seam roof, when the movable column is no longer rising, loosen the liquid filling the gunman had, this completes the setting process with the support of support time, extend the roof, load effect in the single column hydraulic oil increase, compression, live in the column pressure rise, then the single column support force is also called working resistance, according to the principle of hydraulic transmission, it with the roof pressure equal, but changes with time continuity. Is the roof pressure increases, the single column resistance will also increase. It maintains a dynamic balance and roof pressure. When the pressure is increased to the safety valve set pressure adjustment, the supporting force for the time of the largest, known as the rated working resistance pillar. When the roof pressure exceeds the rated working resistance of single column, high pressure liquid single column cavity of the safety valve is opened, the liquid overflow, under a single column to shrink, roof pressure to form a new balance, if a single column under load is lower than the rated working resistance, the single column cavity pressure decreases, the effect of the spring safety valve next, the safety valve is closed, to stop the overflow, so resistance of single column to the roof keep consistent, so as to realize the constant resistance characteristics of single column. This is the pillar bearing class, single column appears when crawling generally occurs in the setting, jitter or ascending or movable column body extends from the cylinder when stop this is the phenomenon of crawling. 


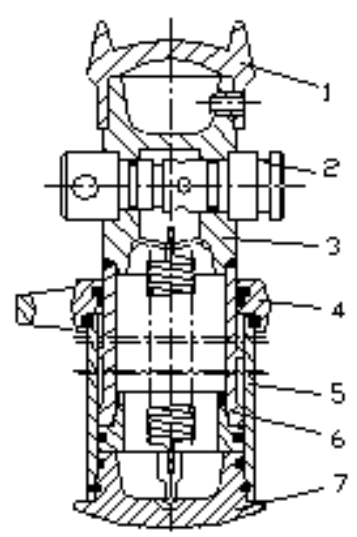

Fig.1 DZ type individual hydraulic prop

\section{The reasons of crawling phenomenon}

Crawling is a speed fluctuation phenomenon that happens under the low speed movement of the hydraulic actuator in the drive system. Hydraulic prop crawling is actually the crawl of the oil cylinder. In fact, the essence is that when an object is moving at low speed in the sliding surface, the discontinuous vibration will be generated by the alternation of stop and slide. The cause of crawling is complex, the most fundamental reason of which is associated with the friction characteristics of the friction surface and the oil compressibility: 1) The change of static and dynamic friction force in hydraulic system. 2) Insufficient rigidity of transmission parts, that is, the elastic deformation of itself and hydraulic compression deformation and mixed with air, etc. 3) The quality of the moving parts is bigger, the inertial force is larger. 4) Speed is too low which is less than the critical speed.

So, the causes of single column crawling are summarized as follows: 1) the air inside the cylinder; 2) the water inside the cylinder; 3) seal is not good; 4) bad lubrication; 5) cylinder and active column surface processing problems; 6) design does not take full account of the corresponding conditions of use.

\section{Analysis of crawling dynamics}

The dynamics model of the creeping phenomenon Establish the mechanical model of the motion of the system, as shown in figure 2.

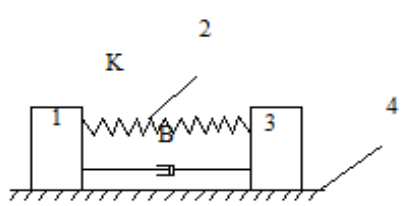

1- driving part; 2-driving medium; 3-follower;' 4-supporting plane

Fig.2 Kinetic model

1 representatives of the active force driving part (active member), to 1 to $\mathrm{V} 0$ (T) moves to the right; stiffness of $\mathrm{K}$ transmission part 2 mainly by the stiffness of hydraulic spring and other transmission link; follower 3 is a rigid body (including piston, piston rod and the load moving parts of hydraulic cylinder), its quality $\mathrm{m}$; $\mathrm{B}$ as the system changes (including damping and viscous damping and friction damping); 4 for supporting rigid surface.

The model calculation A piece of 1 moves to the right distance $\mathrm{x} 1$, the driving force of $\mathrm{kX} 12$ action is equal to the friction through the spring to make the parts, if 1 continue to move to the right, a piece of 2 began the movement to the left, and then set the elapsed time t part moving distance of $2 \mathrm{x}$, differential equation:

$$
m \frac{d^{2} x}{d t}+B \frac{d x}{d t}+F_{d}=k\left(x_{1}+v_{0} t-x\right)
$$


$m \frac{d^{2} x}{d t}$ - Inertial force; $B \frac{d x}{d t}-$ Viscous resistance

$\mathrm{B}$ - the viscous resistance coefficient; $\quad \mathrm{F}_{\mathrm{d}}$ — the dynamic friction

$\mathrm{K}\left(\mathrm{x}_{1}+\mathrm{v}_{\mathrm{o}} \mathrm{t}-\mathrm{x}\right)$ — the driving force; $\quad \mathrm{K}$ — the system stiffness

$m \frac{d^{2} x}{d t}+B \frac{d x}{d t}+k x=k v_{0} t+k x_{1}-F_{d}$

$\Delta \mathrm{F}=\mathrm{kx}_{1}-\mathrm{F}_{\mathrm{d}}$, Static, dynamic friction difference, Type 2 is simplified as

$m \frac{d^{2} x}{d t}+B \frac{d x}{d t}+k x=k v_{0} t+\triangle F$

Type (3) as a Linear Nonhomogeneous Differential Equation, the equation method

$X=e^{-\varepsilon \omega_{\mathrm{n}} \mathrm{t}}\left(c_{1} \cos \omega_{n} t+c_{2} \sin \omega_{n} t\right)+v_{0} t+\frac{\triangle F}{k}-\frac{B v_{0}}{k}$

$\omega_{n}$ The natural frequency of the system, $\omega_{n}=\sqrt{\frac{k}{m}}$

$\varepsilon-$ the system damping ratio, $\varepsilon=\frac{B}{2 m \omega_{n}}=\frac{B}{2 \sqrt{k m}}$ 。

According to the boundary conditions of $\mathrm{t}=0, \frac{d x}{d t}(0)=0, \mathrm{x}(0)=0$.

$\frac{d x}{d t}=v_{0}\left\{1-e^{-\omega_{n} t}\left[\cos \omega_{n} t+(\varepsilon-A) \sin \omega_{n} t\right]\right\}$

A - motion of a homogeneous system, which reflects the effect of $\mathrm{K}, \mathrm{m}, \mathrm{V}_{0}, \Delta \mathrm{F}$ for speed.

$A=\frac{\triangle F}{v_{0} \sqrt{K m}}$

Therefore, do not produce crawling condition is:

$e^{-\varepsilon \omega_{n} t}\left[\cos \omega_{n} t+(\varepsilon-A) \sin \omega_{n} t\right]<1$

$e^{-\varepsilon \omega_{n} t} \sqrt{1+(\varepsilon-A)^{2} \sin \left(\omega_{n} t+\phi\right)}<1$

Consider a cycle, i.e., then type (6) will become:

$e^{-2 \times \varepsilon} \sqrt{1+(\varepsilon-A)^{2}} \leq 1$

Because the $0<\varepsilon<1$

Can be used to obtain the critical speed:

$v_{c}=\frac{\triangle F}{\sqrt{4 \pi \varepsilon k m}}=\frac{g_{n} \sqrt{m}\left(f_{j}-f_{d}\right)}{\sqrt{4 \pi \varepsilon k}}$

$\mathrm{f}_{\mathrm{j}}$-The coefficient of static friction;

$\mathrm{F}_{\mathrm{d}} \longrightarrow$ The dynamic friction coefficient.

Therefore, to avoid crawl phenomenon, the active driving speed, must meet:

$\mathrm{V} \geq \mathrm{V}_{\mathrm{C}}$ or $\mathrm{W} \geq \mathrm{W}_{\mathrm{C}}$

\section{Summary}

Through the kinetic analysis of the crawling phenomenon of hydraulic props, the relevant factors that affect the crawling are $\mathrm{N}, \triangle \mathrm{F}, \mathrm{B}$ and so on. Therefore, the conclusions are drawn as follows:

(1) In the process of design, analysis and manufacturing hydraulic prop, the lowest speed of the live column stretch motion is required to be higher than the critical speed in order to prevent crawling phenomenon.

(2) Reducing the normal force $\mathrm{N}$ on the guide rail can lower the bearing pressure of the bearing surfaces to decrease the critical velocity. 
(3) Reducing the delta F, selecting good sealing and reasonable sealing structure could well eliminate crawling.

(4) Improving the system transmission stiffness can prevent air from mixing with the hydraulic oil

\section{Reference}

[1] Li Guangguo, Lv Shuhua. Hydraulic system fault diagnosis and troubleshooting [M]. Beijing: Ocean Press, 1992185 190.

[2] Ren Weihong, the hydraulic creeping phenomenon by frictional self-excited vibration analysis [J], coal mine machinery, 2003 (10), 44 45.

[3] Liu Jifeng [J], speed fluctuation, crawling and hydraulic system of the modern machinery, 2000 (3), 39 41.

[4] A leksandrov V M,Shmatkova A A. Non-linear unsteady creep of an ice sheet on a hydraulic foundation[J]. J. Appl. Maths Mechs, 196,60(4); 677-680.

[4] Wang Rongjie, Chen Hongwei. Analysis and improvement of Single hydraulic prop creeping phenomenon[J].Hydraulic and pneumatic, 2005 (11), 75-78.

[5] Wang Rongjie, Chen Hongwei. Analysis of the micro hydraulic clamping phenomenon and solutions [J]. Machine \& Hydraulics, 2006, (10), 210-213.

[6] Chen Hongwei. Influence of hydraulic locking factors and diagnosis and treatment [J]. Coal mine mechanical and electrical engineering, 2005 (4), 50-52. 